\title{
ANK/CMT/CP-.84722 Conf-95040/--7
}

\section{LABORATORY TESTING OF LITCO GLASSES}

\author{
A. J. G. Ellison, S. F. Wolf, J. S. Luo, N. L. Dietz, J. B. Bates, W. L. Ebert
}

\author{
Argonne National Laboratory \\ Chemical Technology Division \\ 9700 South Cass Avenue \\ Argonne, IL 60439
}

For presentation at the

American Ceramics Society Meeting

Cincinnati, $\mathrm{OH}$

April 30 - May 4, 1995

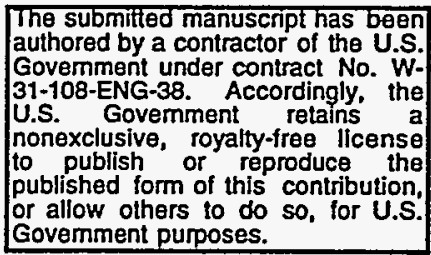

$-$

so, for U.S.

Government purposes.

This work supported by the U.S. Department of Energy, Lockheed Idaho Technologies Company, under contract DE-AC07-94D13223. 


\section{DISCLAIMER}

Portions of this document may be illegible in electronic image products. Images are produced from the best available original document. 


\title{
LABORATORY TESTING OF LITCO GLASSES
}

\author{
Adam Ellison, S. Wolf, E. Buck, J. S. Luo, N. Dietz, J. K. Bates, W. Ebert \\ Chemical Technology Division, Argonne National Laboratory, Argonne, IL 60439
}

\section{INTRODUCTION}

The purpose of this program is to measure the intermediate and long-term durability of glasses developed by Lockheed Idaho Technology Co. (LITCO) for the immobilization of calcined radioactive wastes. The objective is to use accelerated corrosion tests as an aid in developing durable waste form compositions. This is a report of tests performed on two LITCO glass compositions, Formula 127 and Formula 532.

The main avenue for release of radionuclides into the environment in a geologic repository is the reaction of a waste glass with ground water, which alters the glass and releases its components into solution. The reaction rate is highest when glass corrosion products in solution are dilute (the forward rate). As the concentrations of corrosion products in solution increase, the chemical potential gradient between glass and water decreases, slowing the reaction (the interim rate). After prolonged contact with water, the concentrations of dissolved glass components increase to a point where secondary crystalline phases precipitate from solution. If these phases remove components from solution faster than they are replenished by the glass, the concentrations of components in solution will remain at or below the saturation value. This may increase the rate of glass corrosion (the long-term rate). Data concerning the forward rate, the interim rate and the long-term rate are all needed to evaluate glass performance.

These stages in glass corrosion are analyzed by using accelerated laboratory tests in which the ratio of sample surface area to to solution volume, $S A / V$, is varied. At low $S A / V$, the solution concentrations of glass corrosion products remain low and the reaction approaches the forward rate. At higher $S A / V$ the solution approaches saturation levels for glass corrosion products. At very high $S A V$ the solution is rapidly saturated in glass corrosion products and secondary crystalline phases precipitate. Tests at very high $S A N$ provide information about the composition of the solution at saturation or, when no solution is recovered, the identities and the order of appearance of secondary crystalline phases.

Tests were applied to Formula 127 and Formula 532 glasses to provide information about the interim and long-term stages in glass corrosion. Product consistency tests method B (PCT-B [1]) at $S A / V$ of approximately 2,000 and $20,000 \mathrm{~m}^{-1}$ were 
performed to measure the interim corrosion rate of both glasses. PCT-B tests highlight the effects of solution chemistry on glass corrosion, and long-term PCT-B tests can also provide information about secondary phase formation and long-term performance of the glass. Argonne National Laboratory vapor hydration ( $\mathrm{VH}$ [2]) tests were used to determine the identities and order of appearance of secondary crystalline phases, information that is important to the long-term corrosion rate. These tests may indicate whether the presence of secondary crystalline phases increases the glass corrosion rate.

\section{EXPERIMENTAL METHODS}

In a PCT-B test a mass of glass of a particular size fraction is placed in contact with deionized water and heated at fixed temperature for various lengths of time. At the end of the test, the leachate solution is filtered to remove suspended glass particles and the composition of the solution is analyzed. The sample surface area is estimated by assuming that the glass grains are spheres with diameters equal to the average mesh size. On this basis, $S A N$ is $2000 \mathrm{~m}^{-1}$ for $-100+200$ mesh grains in contact with 10 times their mass of water and $20,000 \mathrm{~m}^{-1}$ for $-100+200$ mesh grains in contact with an equal mass of water. The release of components to solution is expressed as normalized release, $\mathrm{NL}_{\mathrm{i}}$ :

$$
N L_{i}=\frac{\text { concentration }}{f_{i} \bullet S A / V}
$$

where $f_{i}$ is the weight fraction of element $i$ in the glass. The value of $N_{\mathrm{i}}$ is an estimate of the mass of glass that reacted to account for the concentration of the element $i$ in solution. PCT-B tests reported in this study were performed at $90^{\circ} \mathrm{C}$ in Teflon $^{\text {TM }}$ vessels.

In the VH test a monolithic sample is placed in contact with water vapor in a sealed vessel at elevated temperature. At relative humidities above $\sim 90 \%$ a thin film of water condenses on the sample. The high SA/V of this condition rapidly saturates the solution with glass corrosion products, resulting in rapid formation of secondary crystalline phases. Over time, growth of secondary crystalline phases changes the composition of the solution, and the crystalline phases may enter into reactions with one another, producing a more stable phase assemblage in the process. At the end of a test, the glass surface is analyzed usinng scanning electron microscopy (SEM) and analytical electron microscopy (AEM) or diffraction to identify the secondary crystalline phases that have formed. The solution evaporates after the test is terminated, so solution analyses cannot be performed. The VH tests in this study were performed at $200^{\circ} \mathrm{C}$.

\section{SAMPLE CHARACTERISTICS}

The compositions of Formula 127 and Formula 532 glasses are shown in Table 1. The composition of Formula 127 was taken from a report by Staples et al. [3]. Formula 127 is a translucent green glass containing 5-10 vol \% crystalline $\mathrm{CaF}_{2}$ 
(fluorite). Most fluorite crystals are 2 to $5 \mu \mathrm{m}$ spherulites distributed 5 to $15 \mu \mathrm{m}$ from one another. Some are in the form of skeletal masses up to $5 \mathrm{~mm}$ in diameter (Fig. 1). Semi-quantitative energy dispersive $\mathrm{x}$-ray spectroscopy (EDS) indicates that the interstitial glass (the dark areas in Fig. 1) is depleted in $\mathrm{Ca}$ and $\mathrm{F}$ relative to the bulk.

The nominal composition of Formula 532 is shown in Table 1. It is a transparent, deep-blue glass with swirls of much darker glass in places and relatively large (1-5 $\mu \mathrm{m})$ blebs of light-colored, undissolved or partially-reacted material. EDS analyses of the light-colored material indicate that its composition is similar to that of the bulk glass though significantly depleted in sodium. Scanning electron microscopy (SEM) and electron diffraction reveal that $5-10 \%$ of the bulk material is the lithium aluminosilicate mineral virgilite, $\mathrm{LiAlSiO}_{8}$. The virgilite crystals have highly irregular faces, indicating that they are fragments of still larger $(>100 \mu \mathrm{m})$ crystals. These larger crystals may have been excluded by crushing the samples for PCT-B tests.

Table 1. Compositions of Formula 127 and Formula 532 Glasses.

\begin{tabular}{|c|c|c|c|c|c|}
\hline & \multicolumn{3}{|c|}{ Formula 127} & \multicolumn{2}{|c|}{ Formula 532} \\
\hline Ele & & at $\%$ & wt \% & at \% & wt \% \\
\hline $\mathrm{Al}$ & 4.1 & 5.1 & 8.0 & 11.6 & \\
\hline B & 1.3 & 0.6 & 5.3 & 3.1 & \\
\hline $\mathrm{Ca}$ & 5.2 & 9.6 & & & \\
\hline $\mathrm{Cu}$ & .6 & 1.8 & 0.5 & 1.6 & \\
\hline $\mathrm{Li}$ & 3.6 & 1.1 & 8.8 & 3.3 & \\
\hline $\mathrm{Na}$ & 4.1 & 4.3 & 4.2 & 5.3 & \\
\hline $\mathrm{Si}$ & 18.2 & 23.5 & 14.3 & 21.8 & \\
\hline $\mathrm{Ti}$ & & & 1.2 & 3.1 & \\
\hline $\mathrm{Zr}$ & 1.8 & 7.5 & & & \\
\hline$F$ & 11.6 & 10.1 & & & \\
\hline 0 & 49.5 & 36.4 & 57.8 & 50.2 & \\
\hline
\end{tabular}

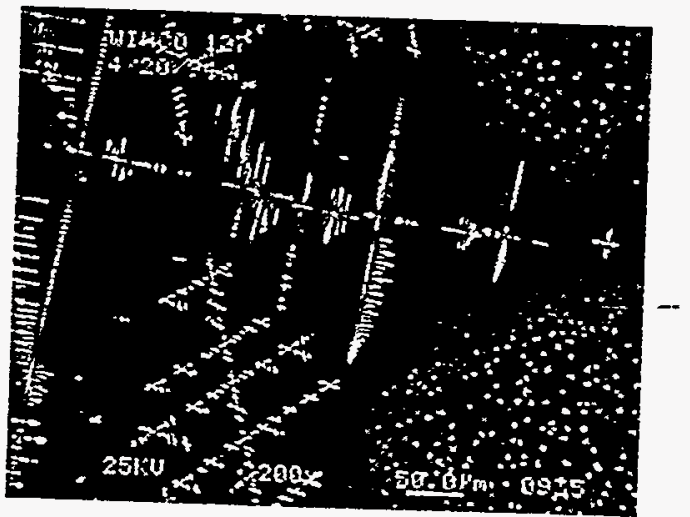

Fig. 1 Electron backscatter image of a polished surface of Formula 127 glass.

\section{FORMULA 127 TEST RESULTS}

Figure 2 is a graph of the normalized releases of $\mathrm{B}, \mathrm{Li}, \mathrm{Na}$ and $\mathrm{Si}$ from Formula 127 glass as a function of the duration of the PCT-B tests. Normalized releases for each element were greater for tests performed at $2,000 \mathrm{~m}^{-1}$ than for tests performed $20,000 \mathrm{~m}^{-1}$ because relatively little glass needs to dissolve at the higher $S A N$ to raise the concentrations of components in solution to near their saturation levels. Normalized releases decreased in the order $\mathrm{Li}, \mathrm{B}>\mathrm{Na}>\mathrm{F}>\mathrm{Si}>\mathrm{Ca}>\mathrm{Al}, \mathrm{Cu}$, $\mathrm{Zr}$. SEM analysis of the PCT-B samples indicated that exposed fluorite crystals 
grow during the course of the tests (Fig. 3). Analytical electron microscopy (AEM) analysis showed that the glass immediately around the fluorite grains was extensively reacted, whereas the bulk glass showed little evidence of reaction and no reaction layer.

After 98 days at $20,000 \mathrm{~m}^{-1}$, calcium silicate crystals started to form, and after 182 days, isolated crystals of a Si-O-F phase (possibly containing $\mathrm{Li}$ or $\mathrm{B}$ ) also formed. No other secondary crystalline phases were identified in solids analyses of PCT-B tests. The rate of release of glass components in $20,000 \mathrm{~m}^{-1}$ tests (Fig. 2) may increase between 98 and 189 days: one-year tests to be terminated later this year may shed light on this issue. If this small increase is real, then the formation of secondary phases has a minor impact on the rate of corrosion of Formula 127 glass.

The first phases to appear in VH tests were calcium silicates, one with a Ca:Si ratio near $1: 1$ and another with a $\mathrm{Ca}: \mathrm{Si}$ ratio $>2: 1$, and a crystal rich in $\mathrm{Si}, \mathrm{O}$ and $\mathrm{F}(\mathrm{Li}$ or $B$ may also have been present). Irregularly-shaped masses of a phase containing $\mathrm{Ca}$ and $\mathrm{O}$ also formed, which may be precipitates of $\mathrm{Ca}(\mathrm{OH})_{2}$. After $14 \mathrm{~d}$ the calcium-rich silicate disappears, and the other calcium silicate was in a reaction relationship with $\mathrm{CaCO}_{3}$, calcite. After $28 \mathrm{~d}$ the main calcium-bearing phase was calcite, which grew to $50-100 \mu \mathrm{m}$ in diameter after $56 \mathrm{~d}$. After $28 \mathrm{~d}$ zirconium also appeared in secondary crystalline phases, a $\mathrm{Ca}-\mathrm{Zr}-\mathrm{F}$ phase (possibly $\mathrm{CaZrF}_{6}$ ) and a $\mathrm{Ca}-\mathrm{Zr}$-Si-O-F phase. The latter was the only significant Si-bearing phase formed in VH tests. Even after $56 \mathrm{~d}$, the glass itself did not appear to undergo very extensive corrosion. Thus, a relatively small amount of glass was reacting to form the phases observed in the VH tests. This supports the conclusion from the PCT-B test data that secondary phases do not have a large impact on the long- term rate of corrosion of Formula 127 glass: the maximum rate of release at $20,000 \mathrm{~m}^{-1}$ from 28 to $98 \mathrm{~d}$ is similar to the long-term rate measured from at $20,000 \mathrm{~m}^{-1}$ from 98 to $182 \mathrm{~d}$.

Nevertheless, Formula 127 appears to absorb or incorporate water during the course of accelerated corrosion tests. Cross-sectioning of grains from PCT-B tests resulted in fragmentation around the borders of the grains, and the depth of fragmentation varied directly with the duration of the experiment. Cross-sectioning grains of unreacted glass did not produce fragmentation, indicating that the nearsurface regions of glass grains from PCT-B tests are more fragile than unreacted glass. Cross-sectioning VH test samples also produced fragmentation of the material in contact with water vapor. Furthermore, the cross-sectioned VH test samples pulled back from the epoxy over time, leaving a gap around the periphery of the glass. The width of the gap increased with the duration of the hydration test. The simplest explanation for this is that Formula 127 glass incorporated water during VH tests, and slowly released it after the tests were completed. Thus, while Formula 127 does not dissolve rapidly in water in accelerated tests, water is incorporated into a layer near the glass surface. 


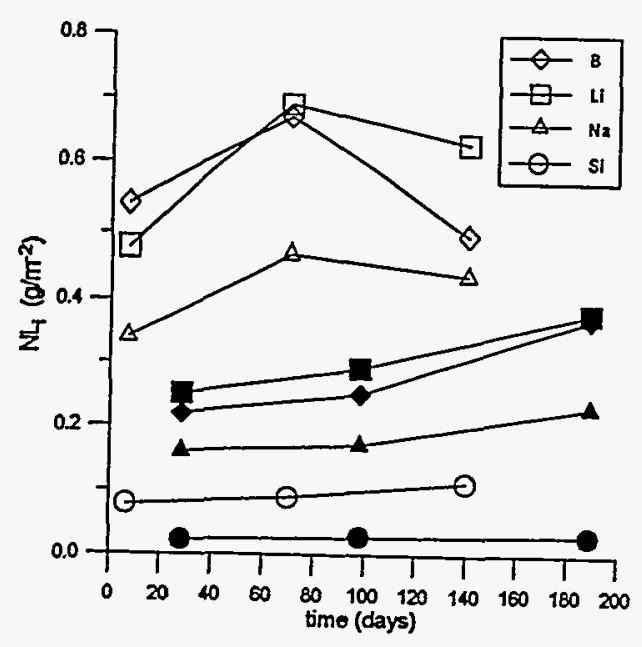

Fig. 2 Normalized releases of B, Li, Na and surface Si of Formula 127 glass in PCT-B tests conducted at $2000 \mathrm{~m}^{-1}$ (open symbols) and $20,000 \mathrm{~m}^{-1}$ (filled symbols).

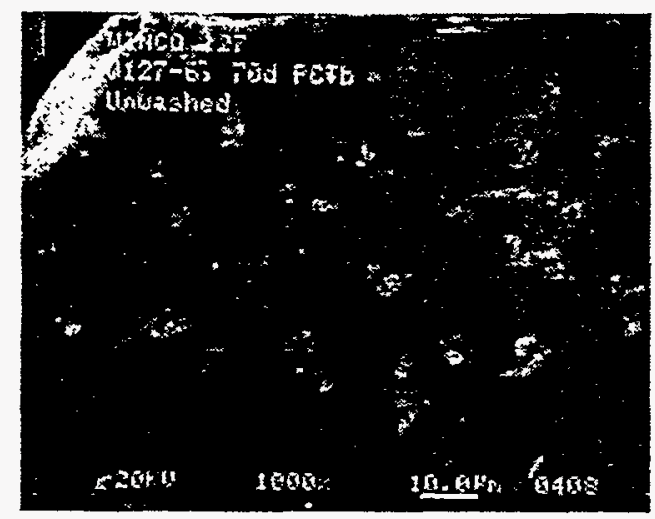

Fig. 3 SEM image of the of a grain of Formula 127 from a PCT-B test conducted at $2000 \mathrm{~m}^{-1}$ for $140 \mathrm{~d}$. Fluorite crystals are the small raised particles embedded in the matrix.FORMULA 532 TEST

\section{RESULTS}

Figure 4 shows normalized releases of $\mathrm{Al}, \mathrm{B}, \mathrm{Li}, \mathrm{Na}$ and $\mathrm{Si}$ from Formula 532 glass as a function of the duration of $2,000 \mathrm{~m}^{-1}$ and $20,000 \mathrm{~m}^{-1}$ PCT-B tests. Normalized releases decreased in the order $\mathrm{B}>\mathrm{Li}>\mathrm{Na}>\mathrm{Al}>\mathrm{Si}$ : in particular, $\mathrm{NL}_{\mathrm{AI}}$ was 20 times greater than for comparable tests performed on Formula 127 glass. The rate of glass dissolution as measured by $\mathrm{NL}_{\mathrm{B}}$ increased after $48 \mathrm{~d}$ at $2,000 \mathrm{~m}^{-1}$ and stayed at this high rate through at least $182 \mathrm{~d}$. By contrast, $\mathrm{NL}_{\mathrm{Si}}$ and $\mathrm{NL}_{\mathrm{Na}}$ decreased after $48 \mathrm{~d}$ at 2,000 $\mathrm{m}^{-1}$ and showed a consistent decrease over the course of the $20,000 \mathrm{~m}^{-1}$ tests. After $49 \mathrm{~d}$ at $2,000 \mathrm{~m}^{-1}$ the zeolite analcime and small crystals with Ti:Al atomic ratio of $1: 2$ (probably $\mathrm{TiAl}_{2} \mathrm{O}_{5}$ ) formed in Formula 532 PCT-B test samples. These and other secondary phases were present in all $\mathrm{PCT}-\mathrm{B}$ tests conducted at $20,000 \mathrm{~m}^{-1}$. At least five different secondary phases have been identified in long-term ( $98 \mathrm{~d}$ ) PCT-B tests, including what appears to be $\mathrm{LiOH} \cdot 2 \mathrm{H}_{2} \mathrm{O}$, and small irregular particles with EDS spectra similar to that of virgilite (these may be a lithium-bearing zeolite, see below). Given the steady decreases in $\mathrm{NL}_{\mathrm{Si}}$ and $\mathrm{NL}_{\mathrm{N}_{\mathrm{a}}}$, analcime and other secondary crystalline phases appear to control the rate of glass dissolution after PCT-B tests of relatively short duration.

The VH tests of Formula 532 glass showed that after $7 \mathrm{~d}$ an alteration layer formed with an average thickness of $30 \mu \mathrm{m}$ and pockets as deep as $50 \mu \mathrm{m}$. The layer was filled with trapezoidal 1-4 $\mu \mathrm{m}$ crystals that are tentatively identified as a lithiumbearing zeolite bikitaite, $\mathrm{Li}_{2} \mathrm{Al}_{2} \mathrm{Si}_{4} \mathrm{O}_{12} \cdot 2 \mathrm{H}_{2} \mathrm{O}$ [4]. The layer was penetrated by deep 


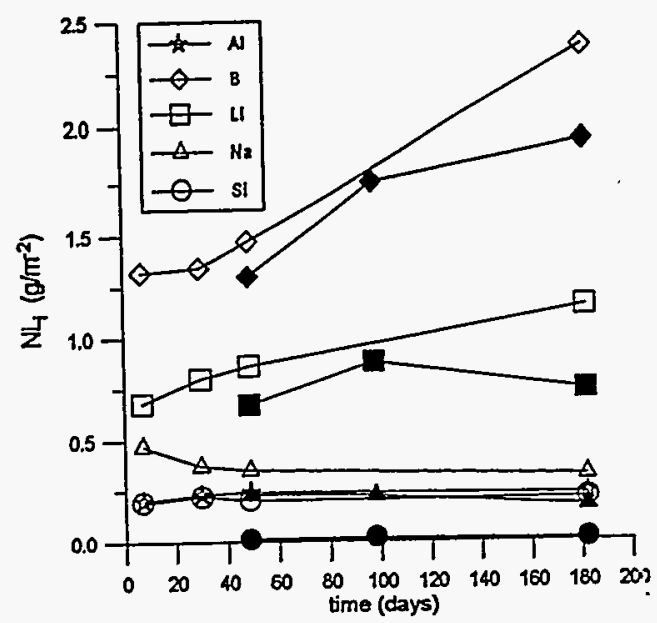

Fig. 4 Normalized releases of $\mathrm{Al}, \mathrm{B}, \mathrm{Li}$, surface of $\mathrm{Na}$ and $\mathrm{Si}$ of Formula 532 glass in PCT-B tests conducted at $2000 \mathrm{~m}^{-1}$ (open symbols) and $20,000 \mathrm{~m}^{-1}$ (filled symbols).

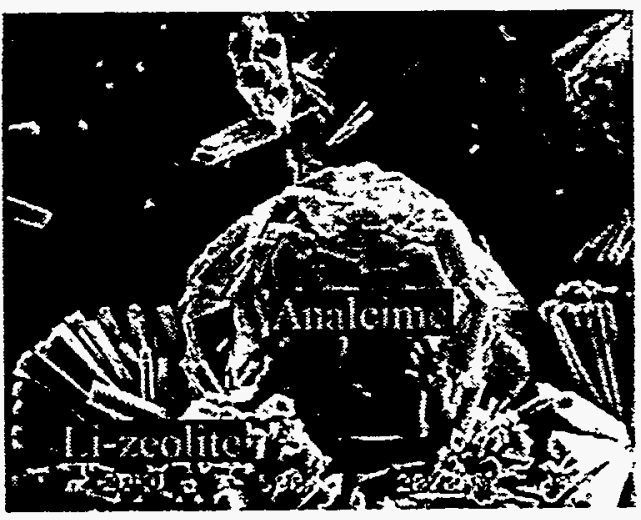

Fig. 5 SEM image of the surface of Formula 532 glass after a $14 \mathrm{~d}$ VH test.

pits that revealed a clay-rich layer below the surface, or in some cases, a second altered layer filled with trapezoidal crystals. Isolated analcime crystals were also found. After $14 \mathrm{~d}$ in a VH test, the surface of Formula 532 was extensively altered, as shown in Fig. 5. The clustered, bladed crystals are the lithium bearing zeolite, and the large faceted crystal in the center of the image is analcime. The noodle-like mat layer underlying all the crystals is a clay. No new phases appeared after $49 \mathrm{~d}$ at $200^{\circ} \mathrm{C}$, but the thickness of the alteration layer increased to approximately $300 \mu \mathrm{m}$ with pockets as deep as $400 \mu \mathrm{m}$ (Fig. 6). The layer consists of alternating layers of lithium-bearing zeolite and sodium-rich, aluminum-depleted material. After $56 \mathrm{~d}$ no unaltered glass remains.

Formation of these phases resulted in complete alteration of Formula 532 glass in $\mathrm{VH}$ tests. The same phases also formed in PCT-B tests, and their appearance coincided with an increase in the glass corrosion rate. These results suggest that Formula 532 moves into the long-term (secondary-phase dominated) stage of glass dissolution very early compared to Formula 127 glass.

\section{SUMMARY}

Formula 127 showed low normalized releases of glass components in PCT-B tests, and VH test data indicated that the secondary crystalline phases did not strongly impact the rate of glass corrosion. The VH test results suggest that a complex, fluoride-rich phase assemblage will eventually form in PCT-B tests. It may be that the main role of secondary crystalline phases is to accommodate fluoride, in which case these phases may not impact the rate of glass dissolution. Fluorite grains on the glass surface appear to control the solution concentrations of $\mathrm{Ca}$ and $\mathrm{F}$. In this 
sense, fluorite behaves both as a primary phase and as a secondary phase, though the fluorite crystals do not appear to increase the rate of corrosion of Formula 127.

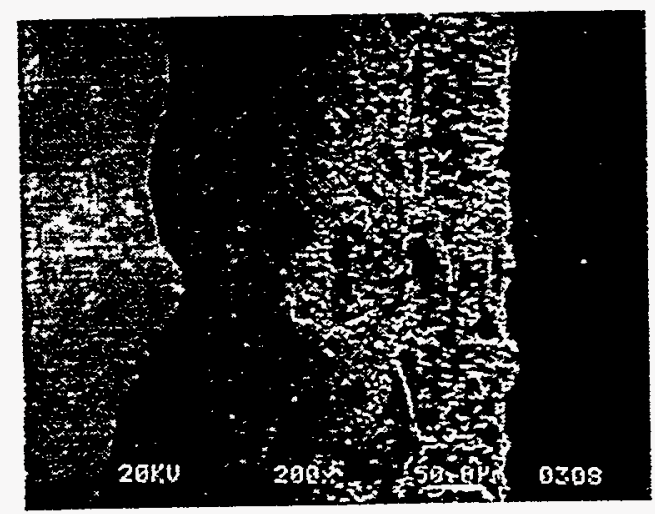

Fig. 6 Cross-section of a monolith of Formula 532 glass after a $49 \mathrm{~d}$ vapor hydration test at $200^{\circ} \mathrm{C}$ unreacted glass is to the left.

Formula 532 showed significantly greater normalized releases for all elements, particularly for aluminum. It is not possible from the solution data to discriminate between $\mathrm{Li}, \mathrm{Al}$ and $\mathrm{Si}$ released from the glass and that released from virgilite, but the integrated effect was to rapidly saturate the solution with $\mathrm{Si}$ (and possibly Al) and drive the formation of secondary crystalline phases. Secondary crystalline phases such as analcime and a lithium-bearing zeolite precipitated relatively early in PCT-B tests and appeared to accelerate the corrosion of Formula 532 glass. VH test results indicate that the lithium-bearing zeolite and analcime are the most important secondary corrosion products for Formula 532, and that a large fraction of the total mass of the glass is converted to these phases as corrosion proceeds.

While secondary crystalline phases are thermodynamically more stable than the glass, the glass must break down to form them, and any components that are not soluble in the secondary phases can potentially be released to solution. This is particularly important in the case of radionuclides: the breakdown of a waste glass into secondary crystalline phases that do not incorporate radionuclides will release them into the environment. The results of this study show the importance of identifying primary and secondary crystalline phases and performing long-term, high-SA/V accelerated tests to analyse their effect on the rate of glass corrosion.

These results also illustrate the value of using a suite of tests with different $S A / V$ to analyze the course of glass corrosion. For example, at a fixed point in time Formula 127 glass is at a very different point in its corrosion path than Formula 532 (e. g., Figs. 2 and 4). Comparing these glasses by using a test with fixed $S A N$ 
run for a fixed time period only provides information about the integrated effects of corrosion up to that point in time, and these effects clearly differ from glass to glass. Thus in $7 \mathrm{~d}$ PCT-B tests at $2000 \mathrm{~m}^{-1}, \mathrm{NL}_{\mathrm{B}}$ values for Formula 127 and Formula 532 differed by a factor of 2.5 , but after $182 \mathrm{~d}$ at $20,000 \mathrm{~m}^{-1}, \mathrm{NL}_{\mathrm{B}}$ values differed by more than a factor of 6 . The feedback between the evolving composition of a solution, the glass, and secondary crystalline phases is very complex, so one must exercise caution in extrapolating durability rankings obtained in short-term leach tests to geologic time scales. Performing different tests over a range of temperatures and $S A N$ is an effective means of evaluating all three stages in glass corrosion and thus, the course of glass corrosion over time.

\section{REFERENCES}

1. Standard Test Methods for Determining Chemical Durability of Nuclear Waste Glasses: The Product Consistency Test (PCT) Standard C1285-94, ASTM, Philadelphia, PA (1994).

2. W. L. Ebert, J. K. Bates and W. L. Bourcier, "The Hydration of Borosilicate Waste Glass in Liquid Water and Steam at $200^{\circ} \mathrm{C}$," Waste Management 11 , 205-221 (1991).

3. B. Staples, H. Cole and D. Pavlica, "Properties of Formula 127 Glass Prepared With Radioactive Zirconia Calcine," Mat. Res. Soc. Symp. Proc. 15, 125-134 (1983).

4. E. M. Flanigen, "Crystal Structure and Chemistry of Natural Zeolites," in Mineralogy and Geology of Zeolites (F. A. Mumpton, Ed.), 19-52 (1981).

\section{DISCLAIMER}

This report was prepared as an account of work sponsored by an agency of the United States Government. Neither the United States Government nor any agency thereof, nor any of their employees, makes any warranty, express or implied, or assumes any legal liability or responsibility for the accuracy, completeness, or usefulness of any information, apparatus, product, or process disclosed, or represents that its use would not infringe privately owned rights. Reference herein to any specific commercial product, process, or service by trade name, trademark, manufacturer, or otherwise does not necessarily constitute or imply its endorsement, recommendation, or favoring by the United States Government or any agency thereof. The views and opinions of authors expressed herein do not necessarily state or reflect those of the United States Government or any agency thereof. 